\title{
Successful embolic protection during temporary circulatory support device removal in a patient who required holding of anticoagulation for postoperative hemothorax
}

Neel K. Ranganath, MD, ${ }^{\mathrm{a}}$ Nader Moazami, MD, ${ }^{\mathrm{a}}$ Cezar S. Staniloae, MD, ${ }^{\mathrm{b}}$ and Kazuhiro Hisamoto, $\mathrm{MD}^{\mathrm{a}}$, New York, NY

\footnotetext{
From the Departments of ${ }^{\mathrm{a}}$ Cardiothoracic Surgery and ${ }^{\mathrm{b}}$ Cardiology, New York University School of Medicine, New York, NY

Disclosures: Authors have nothing to disclose with regard to commercial support.

Received for publication Feb 7, 2018; revisions received April 13, 2018; accepted for publication May 13, 2018 available ahead of print July 3, 2018.

Address for reprints: Kazuhiro Hisamoto, MD, Department of Cardiothoracic Surgery, New York University School of Medicine, 530 First Ave, Suite 9V, New York, NY 10016 (E-mail: kazuhiro.hisamoto@ nyumc.org). J Thorac Cardiovasc Surg 2018;156:e203-4 0022-5223/\$36.00

Copyright (C) 2018 by The American Association for Thoracic Surgery https://doi.org/10.1016/j.jtcvs.2018.05.041
}

The Impella 5.0 (Abiomed, Danvers, Mass) is an intravascular, microaxial temporary circulatory support (TCS) device, and there is a growing body of evidence that this device is a safe and effective treatment for acute cardiogenic shock. However, as was discovered in surgically-implanted mechanical circulatory support devices, thrombosis and bleeding complications remain a major concern. Impella devices use a continuous purge solution $(5 \%$ dextrose with heparin) in addition to systemic therapeutic anticoagulation to prevent pump thrombosis and subsequent embolic events. Despite these precautions, cerebrovascular accident rates might be as high as $7.4 \%$ in certain patient populations. ${ }^{1}$ We present a case of successful embolic protection during Impella removal in a patient with postcardiotomy cardiogenic shock (PCCS) who required holding of anticoagulation for postoperative hemothorax.

\section{CASE REPORT}

A 53-year-old man with newly diagnosed multivessel coronary artery disease was referred for coronary revascularization. Despite preoperative left ventricular ejection fraction of $8 \%$, the patient had good distal targets for revascularization and underwent 4-vessel coronary artery bypass grafting (left internal thoracic to left anterior descending, left radial artery graft from aorta to posterior descending artery, reverse saphenous vein graft from aorta to obtuse marginal sequential to second obtuse marginal) with the understanding that postoperative TCS was probable and that he might ultimately be placed on the ventricular assist device/transplantation pathway if his left ventricle did not adequately recover. Cardiopulmonary bypass was performed via a right axillary graft that could be later used as the outflow cannula for the Impella 5.0 or long-term ventricular assist device, if necessary. Right

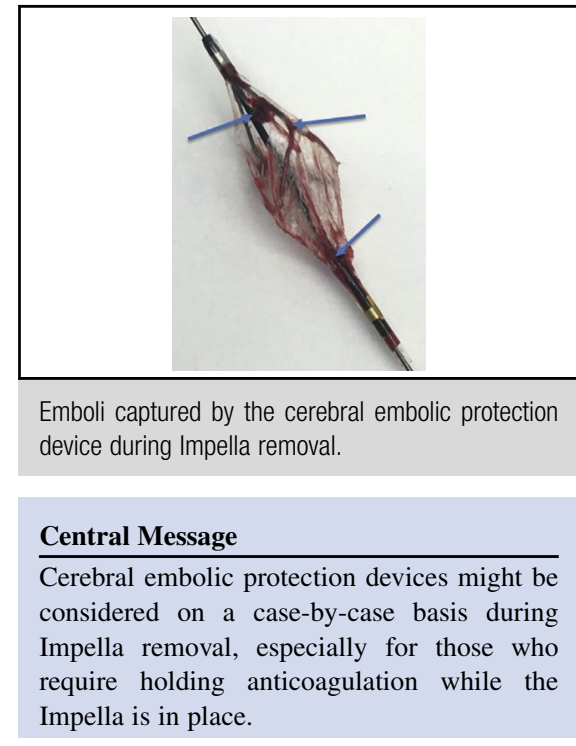

See Editorial Commentary page e205.

axillary access also allows earlier patient mobilization and carries a lower infection risk than femoral access. Therapeutic systemic anticoagulation for the Impella with continuous intravenous heparin infusion was immediately initiated postoperatively and monitored with serial prothromboplastin times. On postoperative day 2, the patient had a ventricular tachycardic arrest requiring defibrillation and cardiopulmonary resuscitation while the Impella remained in place and maintained flow. The patient was diagnosed with left hemothorax on postoperative day 3 , so systemic anticoagulation was held and the purge solution rate was lowered from 25 to $12.5 \mathrm{cc} / \mathrm{h}$. Initial chest tube placement drained 1.2 L of blood; output remained high until he underwent washout of the left chest later that day, and 3 units of packed red blood cells were given for low hematocrit over the same time period. Thus, systemic heparin was not re-established because of concern for ongoing bleeding. The patient returned to the operating room on postoperative day 4 for Impella removal. Because anticoagulation had been discontinued for 36 hours, temporary embolic protection devices were placed prophylactically before Impella removal for presumed 


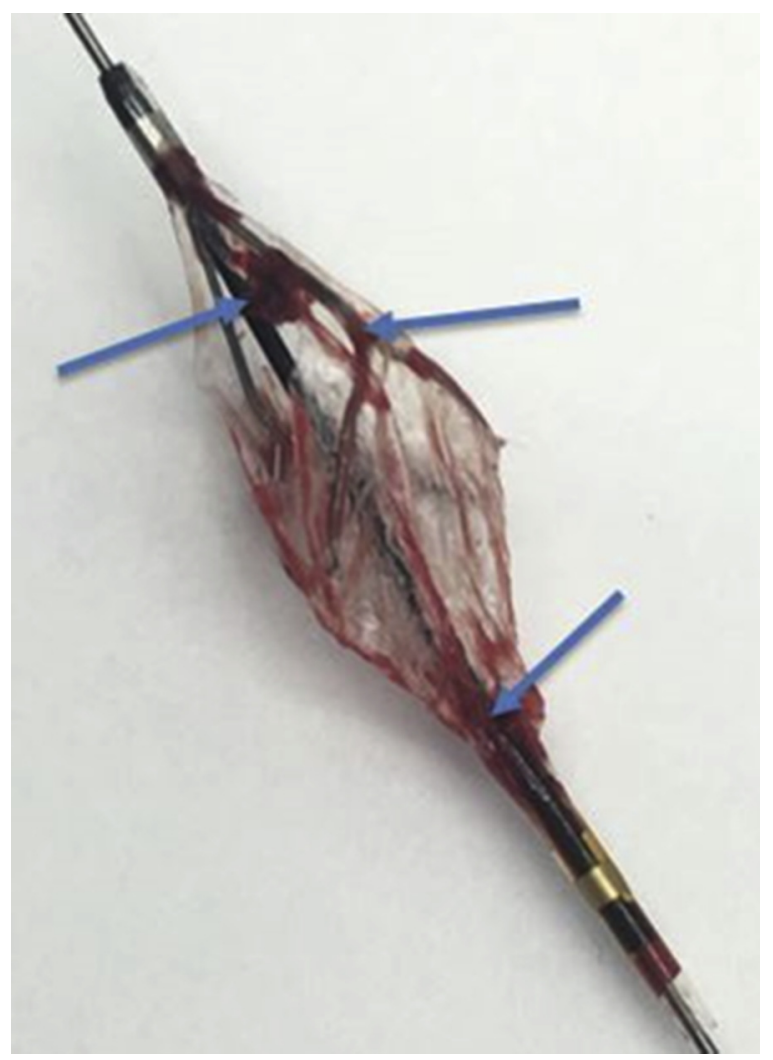

FIGURE 1. A cerebral thromboembolic protection device from the right internal carotid artery is shown after removal. Blue arrows highlight thromboemboli captured by the device.

thromboembolic burden. Emboshield (Abbott Vascular, Santa Clara, Calif) filters were placed in bilateral internal carotid arteries via right femoral artery access. The Impella pump was slowed to $1.0 \mathrm{~L} / \mathrm{min}$ before its removal under fluorescent guidance, and blood was flushed from the graft. When the Impella was removed, the 2 Emboshield filters were retrieved and a significant amount of embolic debris was noted (Figure 1). Predischarge transthoracic echocardiogram showed left ventricular ejection fraction increased to $25 \%$, and the patient was discharged home with no neurological deficit on postoperative day 23 .

\section{CONCLUSIONS}

Percutaneously implanted TCS devices such as the Impella 5.0 are an emerging therapy for patients with acute cardiogenic shock, but thromboembolic complications remain a major concern. A large proportion of studies that have analyzed Impella devices have been in patients who underwent high-risk percutaneous coronary intervention with a relative dearth of evidence on outcomes for Impella-supported patients in PCCS. Patients with PCCS are at higher risk for surgical bleeding, which might require holding anticoagulation and thus exacerbate the risk of thromboembolism. However, the use of cerebral embolic protection for stroke prevention has not been well studied in Impella removal and remains controversial in carotid endarterectomy, carotid stenting, ${ }^{2}$ surgical aortic valve replacement, ${ }^{3}$ and transcatheter aortic valve replacement. ${ }^{4,5}$ In these trials, embolic debris are captured by the devices and a decrease in the number and size of cerebral lesions on magnetic resonance imaging might be noted, but clinical neurological outcomes were essentially unchanged. Although routine placement is not recommended before Impella removal, cerebral embolic protection devices might still be considered on a case-bycase basis, especially in patients at high risk for thromboembolism such as those who require prolonged holding of anticoagulation while the Impella is in place. Considering the quantity and size of debris we observed upon removal of the embolic protection devices, placement of these devices might be beneficial in carefully selected patients before Impella removal. Additional studies are needed to further assess the risk of thromboembolic complications with Impella devices and elucidate which patient groups might benefit from cerebral embolic protection.

\section{References}

1. Lazkani M, Murarka S, Kobayashi A, Seibolt L, Yang T, Pershad A. A retrospective analysis of Impella use in all-comers: 1-year outcomes. J Interv Cardiol. 2017;30:577-83.

2. Kobayashi T, Giri J. The role of embolic protection in carotid stenting progress in cardiovascular diseases (PCVD). Prog Cardiovasc Dis. 2017;59:612-8.

3. Mack MJ, Acker MA, Gelijns AC, Overbey JR, Parides MK, Browndyke JN, et al. Effect of cerebral embolic protection devices on CNS infarction in surgical aortic valve replacement: a randomized clinical trial. JAMA. 2017;318: 536-47.

4. Giustino G, Mehran R, Veltkamp R, Faggioni M, Baber U, Dangas GD Neurological outcomes with embolic protection devices in patients undergoing transcatheter aortic valve replacement: a systematic review and meta-analysis of randomized controlled trials. JACC Cardiovasc Interv. 2016;9:2124-33.

5. Bagur R, Solo K, Alghofaili S, Nombela-Franco L, Kwok CS, Hayman S, et al. Cerebral embolic protection devices during transcatheter aortic valve implantation: systematic review and meta-analysis. Stroke. 2017;48:1306-15. 